\title{
High proportion of mannosidosis and fucosidosis among lysosomal storage diseases in Cuba
}

\author{
C. Menéndez-Sainz ${ }^{1}$, A. González-Quevedo ${ }^{1}$, S. González-García ${ }^{1}$, \\ M. Peña-Sánchez ${ }^{1}$ and R. Giugliani ${ }^{2}$ \\ ${ }^{1}$ Neurobiology Department, Institute of Neurology and Neurosurgery, \\ Havana, Cuba \\ ${ }^{2}$ Serviço de Genética Médica, Hospital das Clínicas de Porto Alegre, \\ Departamento de Genética, \\ Instituto Nacional de Genética Médica Populacional, \\ Universidade Federal do Rio Grande do Sul, Porto Alegre, RS, Brasil \\ Corresponding author: C. Menéndez-Sainz \\ E-mail: cary@infomed.sld.cu
}

Genet. Mol. Res. 11 (3): 2352-2359 (2012)

Received May 17, 2012

Accepted July 3, 2012

Published August 13, 2012

DOI http://dx.doi.org/10.4238/2012.August.13.9

\begin{abstract}
Although lysosomal storage disorders (LSDs) are considered individually rare, as a group they present a non-negligible frequency. Few studies have been made of populational occurrence of LSDs; they have been conducted predominantly on Caucasian populations. We studied the occurrence of LSDs in Cuba. Data from individuals who had been referred to the Institute of Neurology and Neurosurgery in Havana from hospitals all over the country between January 1990 and December 2005 were analyzed. This institute was the only laboratory to provide enzyme-based diagnostic testing for 19 LSDs in Cuba during this period. Occurrence rates were calculated by dividing the number of postnatal diagnoses by the number of births during the study period. The combined occurrence of LSDs in Cuba was 5.6 per 100,000, lower than that reported in other studies conducted on Caucasian populations. The most frequent individual LSDs were: mucopolysaccharidosis type I (1.01 per 100,000) and,
\end{abstract}


surprisingly, alpha-mannosidosis $(0.72$ per 100,000$)$ and fucosidosis $(0.62$ per 100,000$)$. These findings may be related to specific genetic characteristics and admixture of the Cuban population. This is the first comprehensive study of the occurrence of LSDs in Cuba. We conclude that the epidemiology of these diseases can vary regionally, and we stress the need for similar surveys in other Latin American countries.

Key words: Inborn errors of metabolism; Lipidoses; Sphingolipidoses; Lysosomal storage diseases; Mucopolysaccharidosis

\section{INTRODUCTION}

Lysosomal storage diseases (LSDs) form a heterogeneous group of hereditary metabolic disorders, comprising more than 50 different genetic diseases. Most of them involve the dysfunction of lysosomal hydrolases. However, proteins involved in vesicular traffic and the biogenesis of lysosomes can also lead to the disruption of lysosomal function impaired substrate degradation and eventually cell dysfunction. Most LSDs are inherited as autosomal recessive traits, with the exception of Fabry disease, mucopolysaccharidosis (MPS) type II (Hunter disease) and Dannon disease, which have X-linked recessive inheritance. LSDs are progressive diseases usually with severe clinical consequences, where it is not a negligible cause of morbidity and mortality, especially in pediatrics (Parkinson-Lawrence et al., 2010).

Although the LSDs are considered individually rare, their incidence as a group may be considered substantial, ranging from 7.6 per 100,000 in British Columbia (Applegarth and Toone, 2000) to 25 per 100,000 in Portugal (Pinto et al., 2004). In selected populations, higher prevalence values have been reported, such as in Aramco Province, Saudi Arabia (44 per 100,000) (Moammar et al., 2010).

Epidemiological studies on LSDs are relatively scarce in the world. Due to the fact that these are rare diseases, long study periods must be considered to obtain precise data. An additional challenge is that, in most countries, there are several diagnostic centers, making it difficult to collect and unify the information (Giugliani, 2010). Some published studies have focused on specific disorders or groups of disorders that are diagnosed in special reference laboratories, or in selected populations at particularly high risk for certain conditions. Most studies have been conducted in Caucasian populations (Meikle et al., 1999; Poorthuis et al., 1999; Applegarth et al., 2000; Dionisi-Vici et al., 2002; Pinto et al., 2004; Poupetová et al., 2010), with little or no information from countries where mixed ethnic populations are the rule, as is the case in Latin America.

The lack of accurate occurrence data is a handicap for those who want to provide appropriate clinical services for these patients, as they are required to establish management guidelines to be adopted by public or private health services, constituting a key factor in the adoption of screening and treatment programs for LSDs (Fletcher, 2006; Platt and Lachmann, 2009).

After the introduction of the enzyme assays for the diagnosis of LSDs in Cuba in 1986, case reports have been published by several groups (Álvarez-Valiente et al., 1999; Llauradó et al., 2000; Campos-Hernández, 2008), as well as descriptions of case series (Llauradó et al., 1994; Soto et al., 1995; Menéndez et al., 2003; Gutiérrez et al., 2007). 
During the period 1990-2005, all enzyme-based diagnostic testing for LSDs in Cuba was carried out at the Institute of Neurology and Neurosurgery, enabling us to use this information to estimate the occurrence of LSDs in the country.

\section{PATIENTS AND METHODS}

We analyzed data from subjects who had been referred to, or whose blood samples had been sent to the Institute of Neurology and Neurosurgery in Havana, Cuba, between January 1990 and December 2005. Referrals were made by services of Pediatrics, Neurology, Clinical Genetics, Hematology, Cardiology, Orthopedics, Gastroenterology, and Ophthalmology from hospitals all over the country. Because Cuba has universal health care and a consistent standard of medical care throughout the country, we believe that our data provide a fair estimate for the minimal occurrence of these diseases.

In all patients, enzyme assays in leukocytes and/or serum were carried out at our Institute using fluorometric (4-methylumbelliferyl substrates) and spectrophotometric (pnitrophenyl and p-nitrocatechol substrates) methods. These assays were available for 16 lysosomal enzymes, enabling the diagnosis of 19 LSDs. The diagnosis of LSD was finally established by the physician taking into account the clinical and laboratory findings. Data on the number of births in Cuba from 1990 to 2005 (2,367,619 live births) were obtained from the 2005 Health Statistics Yearbook (Anuario Estadístico de Salud en Cuba, 2005). Patient data were compiled according to disorder and year of diagnosis. Incidence rates were calculated by dividing the number of postnatal diagnoses by the number of births during the study period as described by Meikle et al. (1999) and Dionisi-Vici et al. (2002). Confidence intervals (95\%) for the incidences of groups of diseases were calculated employing Statistica 6.0 for Windows (Stat Soft Inc., 2000). Carrier frequency was calculated considering the incidence obtained for each disease, by using the Hardy-Weinberg equilibrium (Mueller and Young, 2001).

\section{RESULTS}

From January 1990 through December 2005, 132 patients were diagnosed with one of 16 specific types of LSDs in Cuba. For three LSDs, there were no diagnoses during the study period (Sandhoff, MPS VII and multiple sulfatase deficiency). Median ages at diagnosis, with the low and high values, as well as the number of cases for each disease are shown in Table 1. In 12 of the 16 disorders diagnosed in the Cuban population during this period (75\%), the median age of diagnosis was below 4 years, although the range of ages in some disorders revealed a considerable variation in the clinical spectrum.

Table 1. Relative frequency and incidence of lysosomal storage diseases in Cuba.
\begin{tabular}{lcccc} 
Disease & No. of patients (1990-2005) & Relative frequency (\%) & Incidence (per 100,000) & Confidence interval (95\%) \\
\hline Lipidosis & 41 & 31.2 & 1.76 & $1.10-2.38$ \\
Mucopolysaccharidoses & 37 & 28.0 & 1.56 & $0.94-1.93$ \\
Glycoproteinoses & 32 & 24.2 & 1.35 & $0.66-1.73$ \\
Mucolipidoses & 11 & 8.3 & 0.46 & $0.13-0.74$ \\
Glycogenosis II & 11 & 8.3 & 0.46 & $0.16-0.95$ \\
Total & 132 & 100.0 & 5.6 & $4.16-6.71$ \\
\hline
\end{tabular}


The number of live births showed a decreasing trend during the study period; while the number of diagnoses varied over the years, with a minimum of two in 2001 and a maximum of 15 in 1996, not related to any specific national or regional screening strategies (Figure 1).

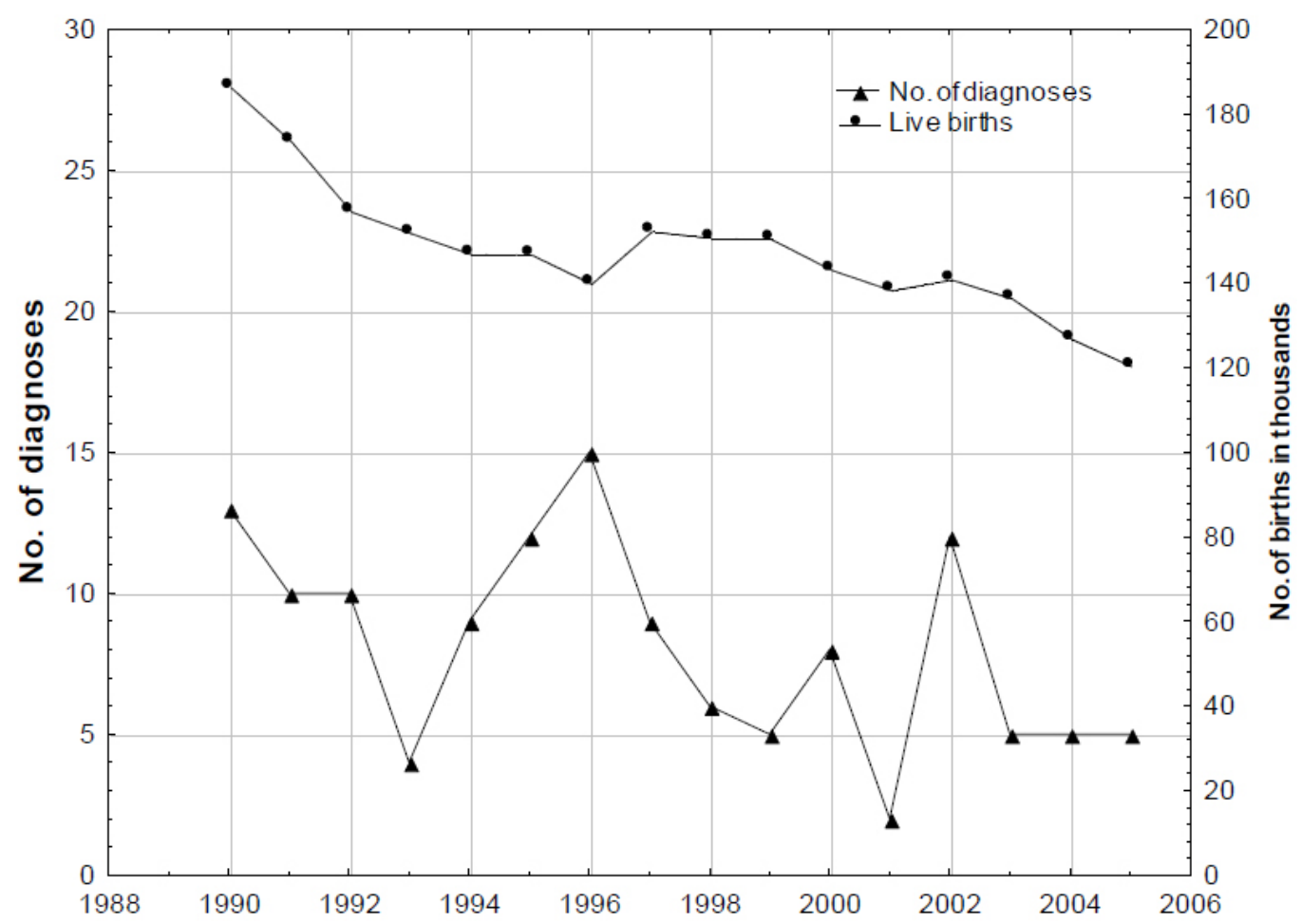

Figure 1. Postnatal diagnoses of lysosomal storage disorders made in Cuba from 1990 through 2005.

The frequency distribution and occurrence of the five main groups of LSDs during the observation period is shown in Table 1. Almost a third of the LSD patients had a lipidosis, followed very closely by MPS and glycoproteinoses; the remaining $16 \%$ suffered from mucolipidosis or glucogenosis II. The combined minimal occurrence for all LSDs was estimated as 5.6 per 100,000 live births $(95 \% \mathrm{CI}=4.16-6.71)$.

Data on patients with lipidoses, MPS and other LSDs detected during the study period - including estimated carrier frequencies - in the Cuban population are presented in Table 2. The incidence and carrier frequencies of these disorders ranged from 1.01 per 100,000 and 1 per 156, respectively, for MPS I, which was the most frequently detected LSD, to 0.04 per 100,000 and 1 per 3741, respectively, for Wolman disease, MPS IV B and Fabry disease. Of note is the fact that the second and third most frequent individual LSDs were $\alpha$-mannosidosis and fucosidosis, usually very rare in most parts of the world. 


\begin{tabular}{|c|c|c|c|c|c|c|c|c|c|}
\hline \multirow[t]{2}{*}{ Diseases } & \multicolumn{4}{|c|}{ Cuba } & \multicolumn{5}{|c|}{ Other countries prevalence/incidence per 100,000 live births } \\
\hline & $\mathrm{N}$ & $\begin{array}{l}\text { Median age } \\
\text { (range) years }\end{array}$ & $\begin{array}{c}\text { Estimated } \\
\text { ocurrence } \\
\text { (per 100,000) }\end{array}$ & $\begin{array}{l}\text { Estimated } \\
\text { carrier } \\
\text { frequency }\end{array}$ & $\begin{array}{c}\text { Australia } \\
\text { (Meikle } \\
\text { et al., 1999) }\end{array}$ & $\begin{array}{l}\text { Czech Republic } \\
\text { (Poupetová } \\
\text { et al., 2010) }\end{array}$ & $\begin{array}{l}\text { Portugal } \\
\text { (Pinto } \\
\text { et al., 2004) }\end{array}$ & $\begin{array}{c}\text { British } \\
\text { Columbia } \\
\text { (Applegarth } \\
\text { et al., 2000) }\end{array}$ & $\begin{array}{c}\text { Netherlands } \\
\text { (Poorthuis } \\
\text { et al., 1999) }\end{array}$ \\
\hline MPS I & 24 & $2(0.3-8)$ & 1.01 & $1 / 156$ & 1.14 & 0.72 & 1.33 & 0.58 & 1.19 \\
\hline MPS III B & 2 & $2.5(2-3)$ & 0.08 & $1 / 1870$ & 0.47 & 0.02 & 0.72 & - & 0.42 \\
\hline MPS IV B & 1 & 6 & 0.04 & $1 / 3741$ & 0 & 0.02 & 0 & - & 0.14 \\
\hline MPS VI & 10 & $2.3(0.3-6)$ & 0.42 & $1 / 374$ & 0.43 & 0.05 & 0.42 & 0.48 & 0.15 \\
\hline MPS VII & 0 & - & 0 & - & 0.05 & 0.02 & 0 & 0.29 & 0.24 \\
\hline MSD & 0 & - & 0 & - & 0.07 & 0.26 & 0.48 & 0.10 & 0.05 \\
\hline GM1 gangliosidosis & 10 & $3(2-26)$ & 0.42 & $1 / 374$ & 0.26 & 0.26 & 0.62 & 0.19 & 0.41 \\
\hline Tay-Sachs & 9 & $1.5(0.5-16)$ & 0.38 & $1 / 415$ & 0.50 & 0.30 & 3.13 & 0.39 & 0.41 \\
\hline MLD & 7 & $3(2-45)$ & 0.29 & $1 / 534$ & 1.09 & 0.69 & 1.85 & 0.58 & 1.42 \\
\hline Niemann-Pick A-B & 2 & $1.5(1-2)$ & 0.08 & $1 / 1870$ & 0.40 & 0.33 & 0.60 & 0.39 & 0.53 \\
\hline Fabry & 1 & 2 & 0.04 & $1 / 3741$ & 0.86 & 0.64 & 0.12 & 0.29 & 0.21 \\
\hline Gaucher & 11 & $8(2-38)$ & 0.46 & $1 / 340$ & 1.75 & 1.13 & 1.35 & 0.39 & 1.16 \\
\hline Sandhoff & 0 & - & 0 & - & 0.26 & 0.19 & 1.49 & 0.29 & 0.34 \\
\hline Wolman & 1 & 16 & 0.04 & $1 / 3741$ & 0.19 & 0.27 & - & 0.58 & 0 \\
\hline$\alpha$-Mannosidosis & 17 & $2(0.6-9)$ & 0.72 & $1 / 220$ & 0.10 & 0.38 & 0.12 & 0.19 & 0.09 \\
\hline Fucosidosis & 15 & $3.5(0.2-17)$ & 0.63 & $1 / 249$ & 0 & 0 & 0 & - & 0.05 \\
\hline Mucolipidosis II & 7 & $1(0.6-2)$ & 0.29 & $1 / 534$ & 0.31 & 0.22 & 0.81 & 0.29 & 0.24 \\
\hline Mucolipidosis III & 4 & $28.5(25-30)$ & 0.17 & $1 / 935$ & & & & & - \\
\hline Glycogenosis II & 11 & $3(0.3-32)$ & 0.46 & $1 / 340$ & 0.69 & 0.37 & 0.17 & 0.90 & 2.0 \\
\hline
\end{tabular}

MPS = mucopolysaccharidosis; MSD = mucosulfatidosis; MLD = metachromatic leukodystrophy.

\section{DISCUSSION}

The overall incidence/prevalence of LSDs reported in the scientific literature ranges from 7.6 per 100,000 for British Columbia in Canada (Applegarth et al., 2000) to 25 per 100,000 for Northern Portugal (Pinto et al., 2004). The minimal ocurrence estimated for Cuba during the study period was 5.6 per 100,000 live births, approximately half of that reported in European countries and Australia (Meikle et al., 1999; Poorthuis et al., 1999; Dionisi-Vici et al., 2002; Sanderson et al., 2006; Stromme et al., 2007; Poupetová et al., 2010), but closer to that reported in British Columbia (Applegarth et al., 2000).

The number of LSDs tested may account for the lower figure that we found. Most of the epidemiological studies that have been published include 24 to 34 disorders, while our study was limited to enzymatic diagnosis of only 19 LSDs. For some diseases, this is a setback due to their relative frequency, which can affect the calculation of a precise combined incidence; such is the case for MPS II, MPS III A, MPS IV A, Krabbe disease, and NiemannPick $\mathrm{C}$ disease. If these enzyme defects would have been assayed, and considering the average prevalence/incidence reported by other authors, our combined incidence would approach $8.0 / 100,000$, which is very similar to that reported in British Columbia (Applegarth et al., 2000), but still lower than the rest of the epidemiological studies (Krasnopolskaya et al., 1993; Meikle et al., 1999; Poorthuis et al., 1999; Pinto et al., 2004; Poupetová et al., 2010). Another is the case for neuronal ceroid lipofuscinoses (NCL), for which relatively high prevalences have been reported in Portugal, Czech Republic and Finland (2.14, 2.29 and 12.5 per 100,000, respectively; Santavuori, 1988; Pinto et al., 2004; Poupetová et al., 2010). Nevertheless, other epidemiological studies have not included NCLs, and still observed higher combined incidences than Cuba (Meikle et al., 1999; Poorthuis et al., 1999). 
Although MPS I was the most frequent LSD diagnosed in Cuba, its occurrence is within the range reported in the literature. The most surprising finding of our study is the relatively high occurrence of $\alpha$-mannosidosis and fucosidosis $(0.72$ and 0.63 per 100,000, respectively), compared to the results published by other authors. The studies carried out in Portugal, Czech Republic, Australia, and Russia did not reveal cases of fucosidosis, while in the Netherlands a very low incidence was encountered $(0.05$ per 100,000) (Table 2). Pámpols et al. (1997) reported 3 cases during a study period of 20 years in Spain in 1997, but 10 years later in another study, Maceira and Atienza (2008) found no cases.

It has been reported that more than $30 \%$ of all fucosidosis cases are attributed to the southern region of Italy, with other regions of high incidence such as Hispanic populations of New Mexico and Colorado in the USA and the Eastern part of Cuba (Llauradó et al., 1994; Willems et al., 1999). Cuba is probably one of the regions with the highest incidence of fucosidosis in the world, most cases being concentrated in the Holguín Province, with an estimated rate of 1.4 per 100,000 in this region, where a high level of consanguinity has been reported (Llauradó et al., 1994). A single mutation Q422X - in the stop codon of exon 8 (FUCA-1) - has been detected, supporting the hypothesis of a founder gene (Willems et al., 1999).

For $\alpha$-mannosidosis there are incidence reports ranging from 0.09 in the Netherlands to 0.38 in the Czech Republic (Table 2), while the incidence observed in this study doubles the highest value. With the available data, it seems that the incidence of $\alpha$-mannosidosis in Cuba is one of the highest reported; with a carrier frequency of $1 / 288$, considerably above those reported in the Czech Republic (Poupetová et al., 2010) and Australia (Poorthuis et al., 1999), $1 / 514$ and $1 / 3920$, respectively.

Summarizing the results of this study, it is of note that the overall minimal occurrence of LSDs in the Cuban population is 5.6 per 100,000, below the values reported in studies performed in other countries/regions. This may be caused 1) by the limited awareness of physicians about these diseases (which could impact referral to reference centers), 2) by the limited number of LSDs tested (19) or 3) by the genetic characteristics and admixture of the Cuban population.

Regarding this last point, the Cuban population is essentially the result of the admixture between Spanish, West Africans and, to a lesser degree, Chinese and Native Americans. Recent studies have demonstrated the important European/African contribution to the genetic composition of the Cuban population, indicating that admixture must be considered (Mendizabal et al., 2008; Cintado et al., 2009; Teruel et al., 2011). Thus, in analyzing the differences between the frequencies of individual LSDs found here and those of other studies, one has to take into account, not only the level of consanguinity and the possible genetic specificities of different populations, which occur worldwide, but also the genetic admixture of the Cuban population, not present in other epidemiological studies.

This study offers the first comprehensive data on the occurrence of LSDs in Cuba, where it is also a pioneer study in Latin America. The data presented here could be of relevance to assess the burden that these disorders impose on our health systems, enabling the design of appropriate management and prevention policies.

\section{ACKNOWLEDGMENTS}

Research supported by the Ministry of Public Health of Cuba. We thank the general practitioners and specialists who cooperated with patient recruitment and diagnosis. 


\section{REFERENCES}

Álvarez-Valiente H, Cuervo N, Dorado J and Menendez C (1999). Síndrome de gangliosidosis infantil generalizada GM1. Presentacion de dos casos. Rev. Neurol. 28: 926-928.

Anuario Estadístico de Salud en Cuba (2005). Available at [http://www.sld.cu/servicios/estadisticas/]. Accessed November $18,2008$.

Applegarth DA, Toone JR and Lowry RB (2000). Incidence of inborn errors of metabolism in British Columbia, 19691996. Pediatrics 105: e10.

Campos-Hernández D, Monaga-Castillo M, Herrera-Vallejera D, Pampín-Delgado Y, et al. (2008). Diagnóstico clínico y bioquímico de un caso de mucopolisacaridosis tipo I. Rev. Biomed. 19: 116-120.

Cintado A, Companioni O, Nazabal M, Camacho H, et al. (2009). Admixture estimates for the population of Havana City. Ann. Hum. Biol. 36: 350-360.

Dionisi-Vici C, Rizzo C, Burlina AB, Caruso U, et al. (2002). Inborn errors of metabolism in the Italian pediatric population: a national retrospective survey. J. Pediatr. 140: 321-327.

Fletcher JM (2006). Screening for lysosomal storage disorders - a clinical perspective. J. Inherit. Metab. Dis. 29: 405-408.

Giugliani R (2010). Inborn errors of metabolism in Latin America: challenges and opportunities. J. Inherit. Metab. Dis. 33: S315-S320.

Gutiérrez García EA, Alonso JLV, Peralta EM, Castilo MM, et al. (2007). Una nueva alternativa diagnóstica: estudio de las enfermedades lisosomales por métodos enzimáticos. Rev. Cuba Med. Gen. Integr. 23: 0-0. Available at [http:// scielo.sld.cu/scielo.php?]. Accessed October 23, 2008.

Krasnopolskaya KD, Mirenburg TV, Aronovich EL, Lebedeva TV, et al. (1993). Diagnosis and prevention of lysosomal storage diseases in Russia. J. Inherit. Metab. Dis. 16: 994-1002.

Llauradó RA, Mar J and González J (1994). Distribución geográfica de la fucosidosis en la provincia de Holguín Cuba. Rev. Esp. Pediatr. 50: 258-260.

Llauradó RA, Willems P, Coucke P, Santos N, et al. (2000). Diagnóstico molecular prenatal de fucosidosis. Presentación de un caso. Rev. Esp. Pediatr. 56: 434-436.

Maceira MC and Atienza G (2008). Detección Precoz de Mucopolisacaridosis y Oligosacaridosis en el Período Neonatal Mediante Cribado Poblacional. Revisión Sistemática. Ministerio de Sanidad y Consumo. Avalia-t N 2006/2008, Madrid.

Meikle PJ, Hopwood JJ, Clague AE and Carey WF (1999). Prevalence of lysosomal storage disorders. JAMA 281: 249-254.

Mendizabal I, Sandoval K, Berniell-Lee G, Calafell F, et al. (2008). Genetic origin, admixture, and asymmetry in maternal and paternal human lineages in Cuba. BMC Evol. Biol. 8: 213.

Menéndez-Sainz C, Zaldivar-Munoz C and Gonzalez-Quevedo A (2003). Mucopolysaccharidosis type I in the Cuban population. Rev. Neurol. 37: 525-528.

Moammar H, Cheriyan G, Mathew R and Al-Sannaa N (2010). Incidence and patterns of inborn errors of metabolism in the Eastern Province of Saudi Arabia, 1983-2008. Ann. Saudi Med. 30: 271-277.

Mueller RF and Young ID (2001). Matemática y Genética de Poblaciones. In: Emery’s Genética Médica (Mueller RF and Young ID, eds.). Marbán Libros, Madrid, 113-124.

Parkinson-Lawrence EJ, Shandala T, Prodoehl M, Plew R, et al. (2010). Lysosomal storage disease: revealing lysosomal function and physiology. Physiology 25: 102-115.

Pámpols T, Briones P, Coll MJ, Chabás A, et al (1997). Investigaciones Encaminadas a la Prevención de las Anomalías Cromosómicas y las Enfermedades Metabólicas Hereditarias. Premio Reina Sofía de Investigación sobre Prevención de las Deficiencias. Editora Real Patronato de Prevención y Atención a Personas con Minusvalía, Barcelona.

Pinto R, Caseiro C, Lemos M, Lopes L, et al. (2004). Prevalence of lysosomal storage diseases in Portugal. Eur. J. Hum. Genet. 12: 87-92.

Platt FM and Lachmann RH (2009). Treating lysosomal storage disorders: current practice and future prospects. Biochim. Biophys. Acta 1793: 737-745.

Poorthuis BJ, Wevers RA, Kleijer WJ, Groener JE, et al. (1999). The frequency of lysosomal storage diseases in The Netherlands. Hum. Genet. 105: 151-156.

Poupetová H, Ledvinova J, Berna L, Dvorakova L, et al. (2010). The birth prevalence of lysosomal storage disorders in the Czech Republic: comparison with data in different populations. J. Inherit. Metab. Dis. 33: 387-396.

Sanderson S, Green A, Preece MA and Burton H (2006). The incidence of inherited metabolic disorders in the West Midlands, UK. Arch. Dis. Child. 91: 896-899.

Santavuori P (1988). Neuronal ceroid-lipofuscinoses in childhood. Brain Dev. 10: 80-83.

Soto G, Algora AE, Barrios B and Heredero L (1995). Pesquisaje de mucopolisacáridos en población infantil de riesgo. Rev. Cub. Ped. 67: 0-0. Available at [http://scielo.sld.cu/scielo.php]. Accessed October 23, 2008. 
Stromme P, Kanavin OJ, Abdelnoor M, Woldseth B, et al. (2007). Incidence rates of progressive childhood encephalopathy in Oslo, Norway: a population based study. BMC Pediatr. 7: 25.

Teruel BM, Rodriguez JJ, McKeigue P, Mesa TT, et al. (2011). Interactions between genetic admixture, ethnic identity, APOE genotype and dementia prevalence in an admixed Cuban sample; a cross-sectional population survey and nested case-control study. BMC Med. Genet. 12: 43.

Willems PJ, Seo HC, Coucke P, Tonlorenzi R, et al. (1999). Spectrum of mutations in fucosidosis. Eur. J. Hum. Genet. 7: 60-67. 